\title{
Design and Implementation of Adaptive Fuzzy Controller for Speed Control of Brushless DC Motors
}

\author{
N.Senthil Kumar \\ Professor, EEE Department \\ Mepco schlenk Engineering College, \\ Sivakasi, Tamilnadu India
}

\author{
C.Senthil Kumar \\ Assistant Professor, EEE Department, \\ PSR Engineering College, Sivakasi \\ Tamilnadu, India
}

\begin{abstract}
This paper presents the design and implementation of an adaptive fuzzy logic controller for the speed control of brushless dc motors. The proposed system uses an adaptation of the slope of the membership functions of the variables used in the conventional fuzzy controller based on the magnitude of the error. A simulation analysis of the fuzzy controller and the adaptive fuzzy controller are done and their performances are compared. Simulation results of both fuzzy and adaptive fuzzy controllers are presented. The adaptive fuzzy controller is better than the fuzzy controller based on the performance parameters considered. An experimental implementation of the designed adaptive fuzzy controller on an embedded microcontroller is also presented.
\end{abstract}

\section{Keywords}

Brushless DC motor, Fuzzy controller, Adaptive fuzzy controller, microcontroller.

\section{INTRODUCTION}

Recently, permanent magnet brushless dc motor (PMBLDC) is very popular because of its attractive features such as high starting torque, high efficiency, low maintenance cost, absence of mechanical commutator, high speed operation, low volume to torque ratio, elimination of sparking and electromagnetic disturbances, noise.

A PMBLDC motor is inside out construction of DC motor. The efficiency is likely to be higher than DC motor of equal size and the absence of commutator and brushes, reduces the motor length. Hence the lateral stiffness of the motor is increased, allowing for high speeds $[1,2]$. The power electronic converters required in brushless dc motor are similar in topology to the PWM inverter used in induction motor drives.

Nowadays brushless dc motors are used in various applications such as defense, industries, robotics, etc. In these applications, motor should be precisely controlled so as to give desired performance. The classical controller need accurate mathematical model of the system and can perform well only under linear condition. Since the PMBLDC motor is highly coupled non-linear multivariable system, it is difficult to obtain its accurate mathematical model. Hence there is a need for intelligent controller. So an attempt is made to develop fuzzy controller for PMBLDC motor.

The fuzzy logic controller (FLC) is indeed capable of providing the high accuracy required by high performance drive system without the need of mathematical model [3, 4]. FLC accommodates non-linearity without utilization of mathematical model $[5,6]$. The fuzzy logic controller uses fuzzy logic as a design methodology, which can be applied in developing nonlinear system for embedded control. Simplicity and less intensive mathematical design requirements are the most important features of the FLC.

Fuzzy logic control is derived from fuzzy set theory introduced by Zadeh in 1965. In fuzzy set theory, the transition between membership and non-membership can be gradual. Therefore, boundaries of fuzzy sets can be vague and ambiguous, making it useful for approximate systems. Fuzzy Logic controller is an attractive choice when precise mathematical formulations are not possible [7, 8].

\section{PROPOSED SYSTEM}

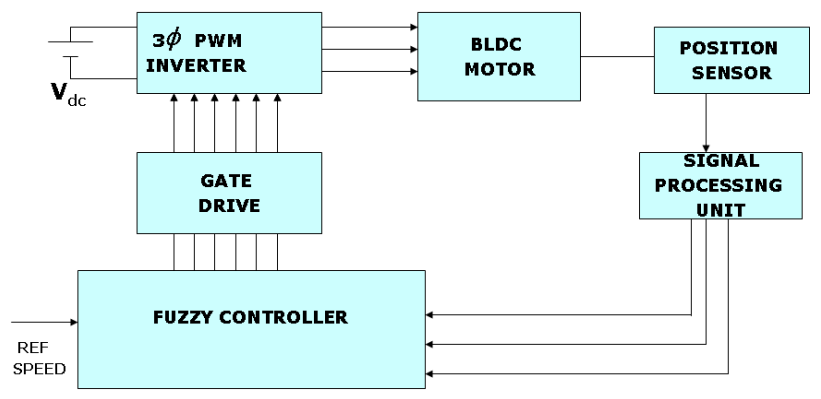

Figure 1. Proposed system.

Figure 1 shows the block diagram of proposed system. The system above is composed of brushless dc motor, six step inverter, gate drive for inverter, fuzzy controller and switching logic. Due to the presence of parameter variation and load disturbance in a BLDC motor, closed loop control is necessary, to obtain a desirable behavior. BLDC motor has three phase windings on stator and Permanent Magnet on rotor. In order to define the shaft position, rotor position sensor is necessary. The sensor senses the rotor shaft position and signals. The processed signals are given to the fuzzy controller. The output of the controller is used to provide switching signals for the inverter from which the speed of the motor can be controlled.

\section{FUZZY AS A CONTROL TOOL}

Generally PI controller is widely used in BLDC motor control; however it does not give satisfactory results when control parameters and loading condition changes rapidly [3]. The fuzzy logic controller (FLC) will guarantee a stable operation, even if there is a change in motor parameters and load disturbances. The 
reason is obvious; any control system maps the input space to the output space. Generally, a desired set of outputs are calculated for a given set of inputs. This mathematical calculation is represented with a formula, which demonstrates the system behavior. However, this mathematical formula may be too complex to use for the real world issues. In these cases, fuzzy logic provides a useful methodology to create a practical solution for controlling complex systems. It is not necessary to know the exact model of such complex systems in order to design a FLC. It is sufficient to understand the general behavior of the system. Fuzzy logic enables the designer to express the general behavior of the systems in an easier (linguistic) manner where it is allowed to use words and sentences instead of numbers and equations. This is accomplished by forming IF-THEN rules which describe the characteristics of the system. High degree of automation and robust nonlinear control is also possible by means of fuzzy controller.

\section{DESIGN OF FUZZY CONTROLLER}

The purpose of the speed control of a brushless dc motor is to arrange the applied voltage in order to reach the reference speed. An error is determined by the difference between the actual speed and the reference speed. The applied voltage should be changed by increasing or decreasing the duty cycle of power transistors in order to minimize the error[4,5].In order to accomplish this task fuzzy controller is designed. Error and change in error are the inputs for the fuzzy controller whereas the output of the controller is change in duty cycle. Two input single output Mamdani type of fuzzy controller with 25 rules is designed for this work. Design of fuzzy controller involves three steps namely fuzzification, inference mechanism and defuzzification.

\section{Fuzzification}

Fuzzy logic uses linguistic variables instead of numerical variables. The process of converting a numerical variable in to a linguistic variable is called fuzzification. Five linguistic variables Negative Big(NB), Negative Small(NS), Zero(Z), Positive Small(PS), Positive Big(PB) are used in this work. Triangular membership function is assigned for input and output variables defined in different universe of discourses. They are shown below.

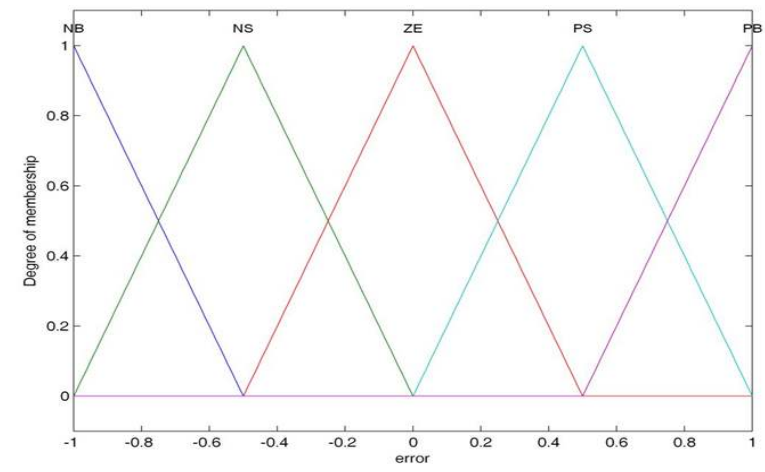

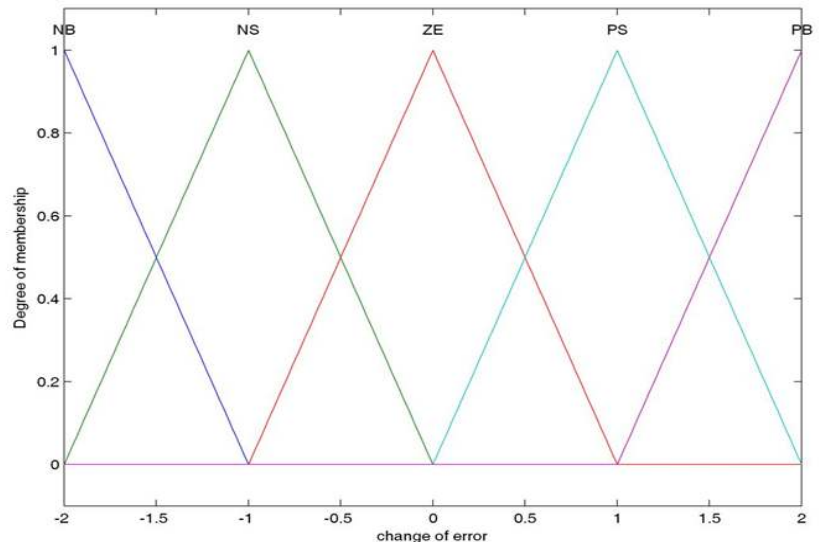

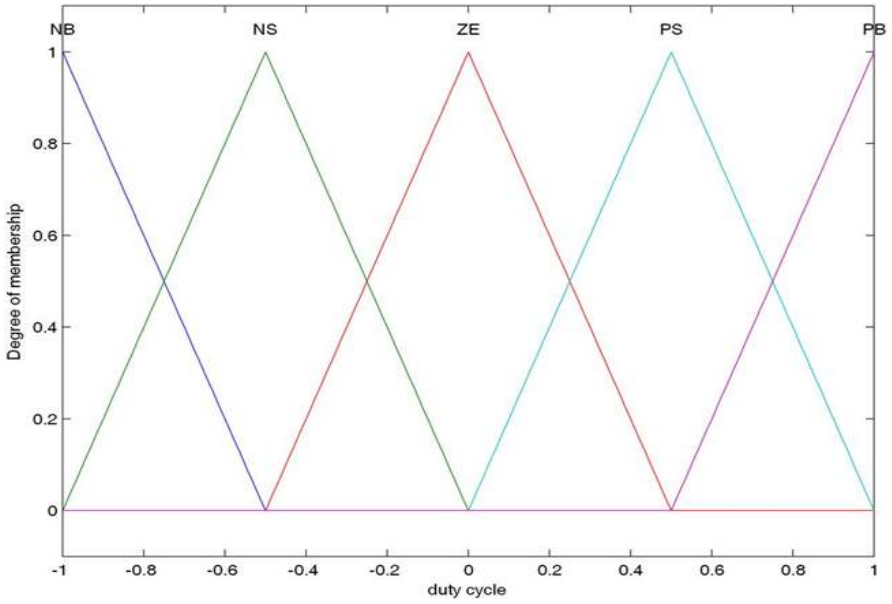

Fig.2 Membership functions used for fuzzy controller.

\subsection{The inference mechanism}

Table1: Rule base

\begin{tabular}{|l|l|l|l|l|l|}
\hline CE E & NB & NS & Z & PS & PB \\
\hline NB & NB & NB & NB & NS & Z \\
\hline NS & NB & NB & NS & Z & PS \\
\hline Z & NB & NS & Z & PS & PB \\
\hline PS & NS & Z & PS & PB & PB \\
\hline PB & Z & PS & PB & PB & PB \\
\hline
\end{tabular}


The rules are in the following format. If error is $\mathrm{Ai}$, and change in error is Bi then output is Ci. Here the if "part" of a rule is called the rule-antecedent and is a description of a process state in terms of a logical combination of atomic fuzzy propositions. The "then" part of the rule is called the rule consequent and is a description of the control output in terms of logical combinations of fuzzy propositions. The rule table for the designed fuzzy controller is given in the table 1.From the rule table the rules are manipulated as follows $[4,5]$. output is NB

Rule1: If error is $\mathrm{NB}$, and change in error is $\mathrm{NB}$ then output is NB

Rule2: If error is $\mathrm{NB}$, and change in error is NS then output is NB

Rule3: If error is $\mathrm{NB}$, and change in error is $\mathrm{Z}$ then output is $\mathrm{PB}$

Rule25: If error is $\mathrm{PB}$, and change in error is $\mathrm{PB}$ then

\subsection{Defuzzification}

The reverse of fuzzification is called defuzzification. The use of FLC produces required output in a linguistic variable. According to real world requirements, the linguistic variables have to be transformed to crisp Output. There are many methods of defuzzification. Centroid method of defuzzification is used in this work. The defuzzified output is obtained by the following equation

$$
\dot{\mathrm{Z}}=\frac{\int \mu(z) z d z}{\int \mu(z) d z}
$$

\section{Adaptive Fuzzy Controller}

Adaptive fuzzy controller is one which provides provision for changing the parameters of fuzzy system based on performance index. Parameters of adaptation are

$$
\begin{aligned}
& \circ \text { the scaling factors for each variable. } \\
& \circ \text { the fuzzy set representing the meaning of } \\
& \text { linguistic variables. } \\
& \circ \text { the if-then rules.[5] }
\end{aligned}
$$

In this work the slope of the membership function of error and change in error are changed according to the values of error. When the error lies in the range -1 to -0.5 and 0.5 to 1 , the membership function shown in figure 3 is used whereas when the error lies in the range -0.5 to 0.5 , the membership function shown in figure 4 is used. This is accomplished in simulation by using embedded Matlab function in simulink tool box.

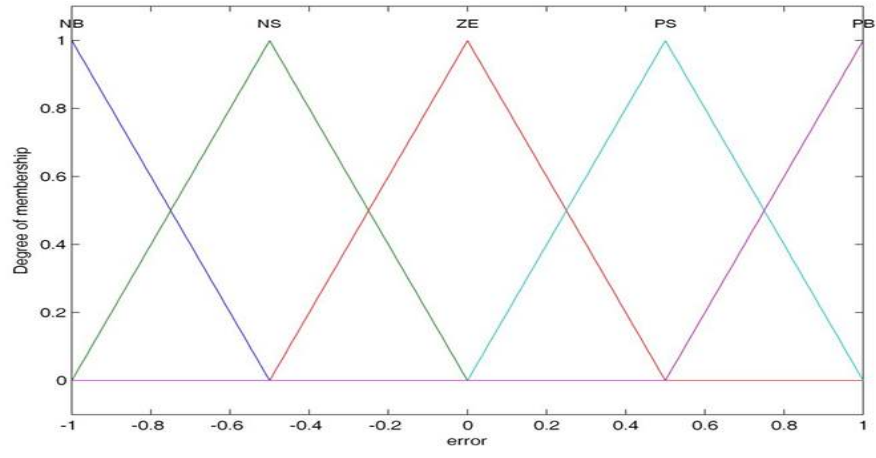

Fig.3 Membership function used for error in the range -1 to 0.5 and 0.5 to 1

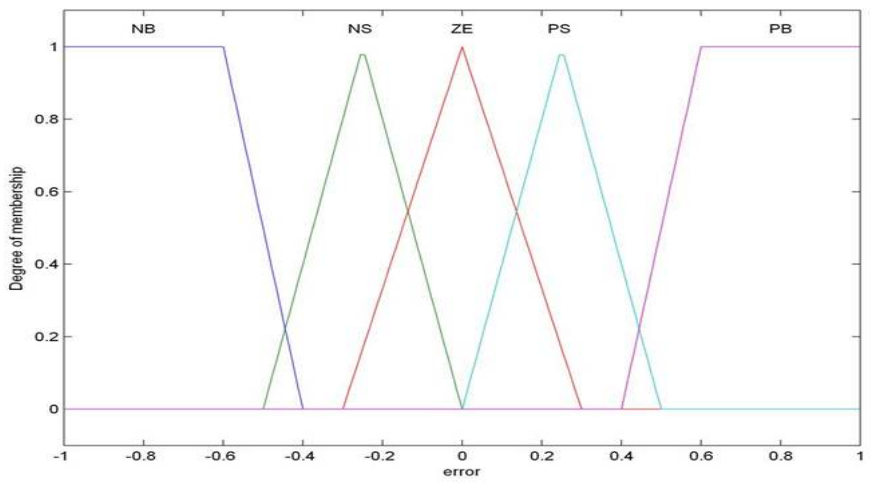

Fig.4 Membership function used for error in the range $\mathbf{- 0 . 5}$ to 0.5

\section{Computer Simulation}

The closed loop model of the machine was developed and simulated with fuzzy controller. The simulation is carried by using the software package MATLAB. The Simulink block diagram used is shown in figure 5. Figure 6 shows the structure of the fuzzy controller used. The Simulink model has the BLDC model, which is fed from the inverter. Inverter receives the gate pulses from the PWM Gate block. This block in turn receives two inputs - switching signal generated from encoder and duty cycle generated from the fuzzy controller block. The step change in speed reference and load is given at the pre-specified time. The controller performance is tracked by observing the speed after the input command.

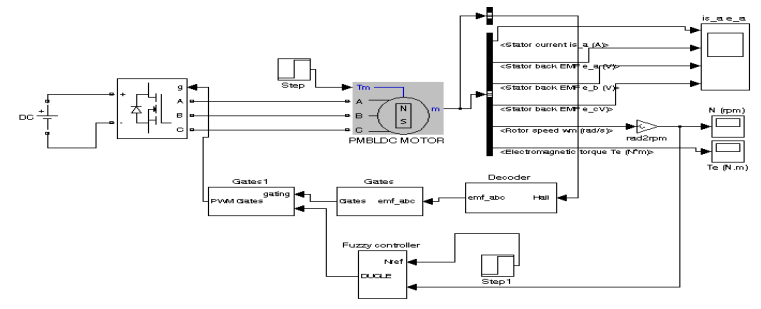

Fig.5 Simulink model of proposed system 


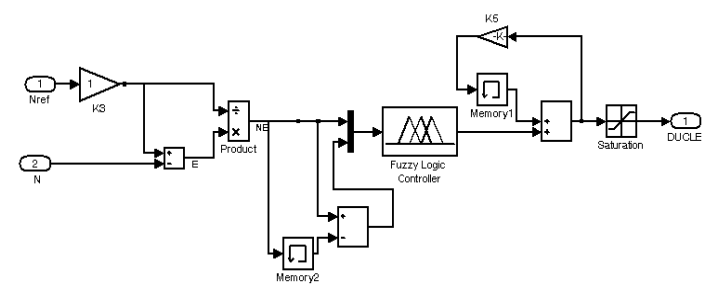

Fig.6 Structure of fuzzy controller used in this work

\section{Simulation Results}

The simulation results for step change in reference speed with the fuzzy controller are shown in figures 7,8 and 9. Figure 7 shows the simulated response for the step change in reference speed from 0 to $100 \%$ of the rated value at $0 \mathrm{sec}$ and $100 \%$ to $50 \%$ of the rated value at $1 \mathrm{sec}$. Figure 8 shows the simulated response for the step change in reference speed from 0 to $50 \%$ of the rated value at 0 sec and $50 \%$ to $100 \%$ of the rated speed value at $1 \mathrm{sec}$. Figure 9 shows the simulated response for the step change in reference speed from 0 to $75 \%$ of the rated value for $2 \mathrm{~s}$ with load torque changed from 0 to $100 \%$ of the rated value at $1 \mathrm{sec}$. Simulation results for the same conditions with adaptive fuzzy controller are shown in figures 10,11 and 12 respectively.

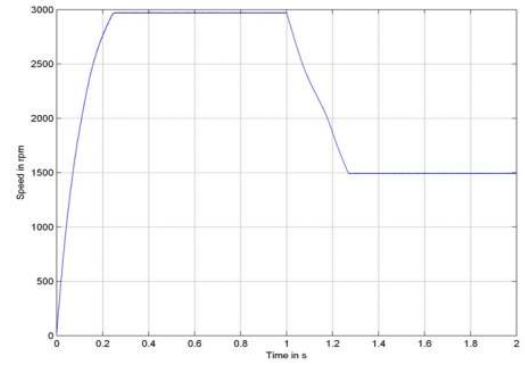

Fig.7 Simulated response of fuzzy controller for step change in reference speed from rated value to $50 \%$ of the rated value at 1 sec

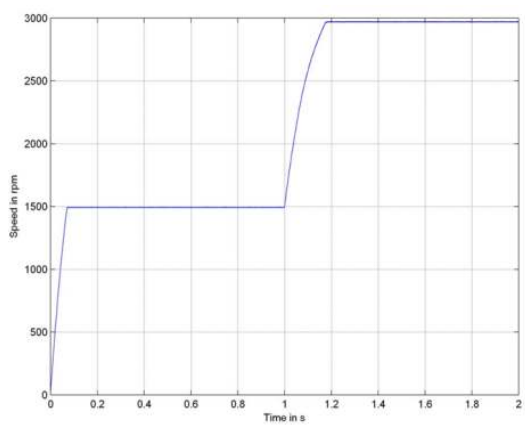

Fig.8 Simulated response of fuzzy controller for step change in reference speed from $50 \%$ of the rated value to the rated value at $1 \mathrm{sec}$

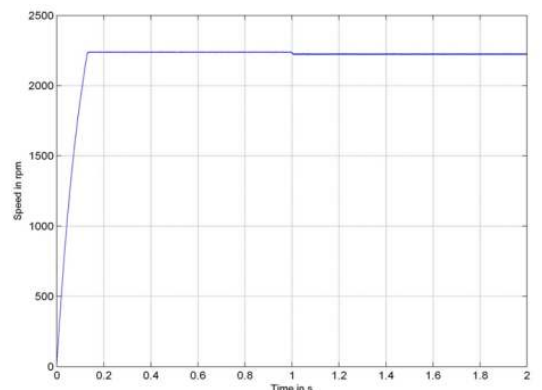

Fig.9 Simulated response of fuzzy controller for change in speed with load change from 0 to $100 \%$ of the rated value at 1sec.

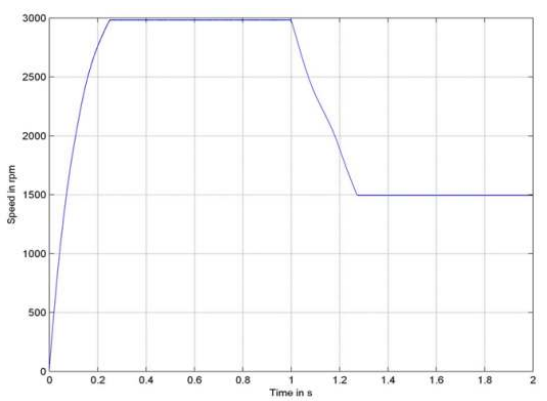

Fig.10 Simulated response of adaptive fuzzy controller for step change in reference speed from rated value to $50 \%$ of the rated value at $1 \mathrm{sec}$

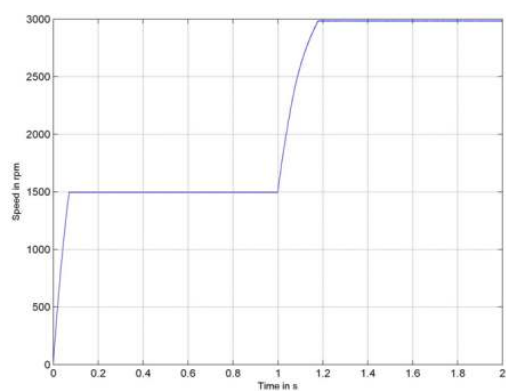

Fig.11 Simulated response of adaptive fuzzy controller for step change in reference speed from $50 \%$ of the rated value to the rated value at $1 \mathrm{sec}$

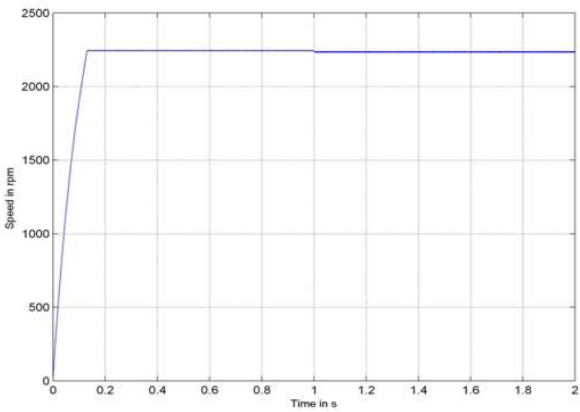


Fig.12 Simulated response of adaptive fuzzy controller for change in speed for a load change from 0 to $100 \%$ of the rated value at 1 sec.

\section{Performance Comparison}

The performance of the system with fuzzy and adaptive fuzzy controller is measured in terms of rise time and steady state error. The performance comparison chart for different reference speeds for no load condition is given in table 2. Table 3 gives the comparison of the performance parameters under loaded condition.

Table 2: Performance comparison under no load

\begin{tabular}{|c|c|c|c|c|}
\hline \multirow{2}{*}{$\begin{array}{l}\text { Step change } \\
\text { in reference } \\
\text { speed }\end{array}$} & \multicolumn{2}{|c|}{$\begin{array}{l}\text { Fuzzy } \\
\text { controller }\end{array}$} & \multicolumn{2}{|c|}{$\begin{array}{l}\text { Adaptive Fuzzy } \\
\text { Controller }\end{array}$} \\
\hline & $\begin{array}{l}\text { Rise } \\
\text { time in } \\
\text { sec }\end{array}$ & $\begin{array}{l}\begin{array}{l}\text { Steady } \\
\text { state } \\
\text { error }\end{array} \\
\% \quad \text { in } \\
\%\end{array}$ & $\begin{array}{l}\text { Rise } \\
\text { time in } \\
\text { sec }\end{array}$ & $\begin{array}{l}\begin{array}{l}\text { Steady } \\
\text { state } \\
\text { error }\end{array} \\
\quad \quad \text { in } \\
\% \quad\end{array}$ \\
\hline $\begin{array}{l}0 \text { to } 100 \% \text { of } \\
\text { rated value }\end{array}$ & 0.1779 & 0.866 & 0.1779 & 0.4 \\
\hline $\begin{array}{l}0 \text { to } 75 \% \text { of } \\
\text { rated value }\end{array}$ & 0.1029 & 0.355 & 0.1029 & 0.177 \\
\hline $\begin{array}{l}0 \text { to } 50 \% \text { of } \\
\text { rated value }\end{array}$ & 0.0567 & 0.333 & 0.0567 & 0.12 \\
\hline $\begin{array}{l}0 \text { to } 25 \% \text { of } \\
\text { rated value }\end{array}$ & 0.0242 & 0.053 & 0.0242 & $0.053^{-}$ \\
\hline
\end{tabular}

Table 3: Performance comparison under $100 \%$ of the load torque applied

\begin{tabular}{|c|c|c|c|c|}
\hline \multirow{2}{*}{$\begin{array}{l}\text { Step change } \\
\text { in reference } \\
\text { speed }\end{array}$} & \multicolumn{2}{|c|}{$\begin{array}{l}\text { Fuzzy } \\
\text { controller } \\
\end{array}$} & \multicolumn{2}{|c|}{$\begin{array}{l}\text { Adaptive Fuzzy } \\
\text { Controller }\end{array}$} \\
\hline & $\begin{array}{l}\text { Rise } \\
\text { time in } \\
\text { sec }\end{array}$ & $\begin{array}{r}\text { Steady } \\
\text { state error } \\
\text { in \% }\end{array}$ & $\begin{array}{l}\text { Rise } \\
\text { time in } \\
\text { sec }\end{array}$ & $\begin{array}{r}\text { Steady } \\
\text { state error } \\
\text { in } \% \\
\end{array}$ \\
\hline $\begin{array}{l}0 \text { to } 75 \% \text { of } \\
\text { rated value }\end{array}$ & 0.1700 & 0.933 & 0.1700 & 0.466 \\
\hline $\begin{array}{l}0 \text { to } 50 \% \text { of } \\
\text { rated value }\end{array}$ & 0.0810 & 0.706 & 0.0810 & 0.333 \\
\hline $\begin{array}{l}0 \text { to } 25 \% \text { of } \\
\text { rated value }\end{array}$ & $\mathbf{0 . 0 3 3 7}$ & 0.373 & $\mathbf{0 . 0 3 3 7}$ & $0.066^{-}$ \\
\hline
\end{tabular}

\section{Experimental Implementation}

The fuzzy controller was implemented practically using dsPIC30F4011 processor and programming it in C language. A six switch inverter was constructed and used to test the controller designed on a $24 \mathrm{~V}$ BLDC motor. The processor selected has the advantages of Enhanced flash program memory, selfreprogrammable under software control, limited number of instructions with faster execution speed, programmable code protection, selectable power management modes and low power consumption. Port B of the processor receives input from the position sensors. Based upon the values of hall position sensor signals, PWM pulses are produced at the Port E Pins 0 to 5.

The speed is calculated from the hall sensor inputs using timers. Then the controller routine will decide the new duty cycle. The duty cycle of the PWM generated can be varied by changing the control word written to the corresponding special function register in the processor. By varying the duty cycle of the pulses applied to the inverter, the speed of the PMBLDC motor is controlled effectively. In this work, low side pulses are made as PWM pulses whereas high side drivers are kept at active high or low state as and when required. The flowchart of the control program is given in figure 13 .

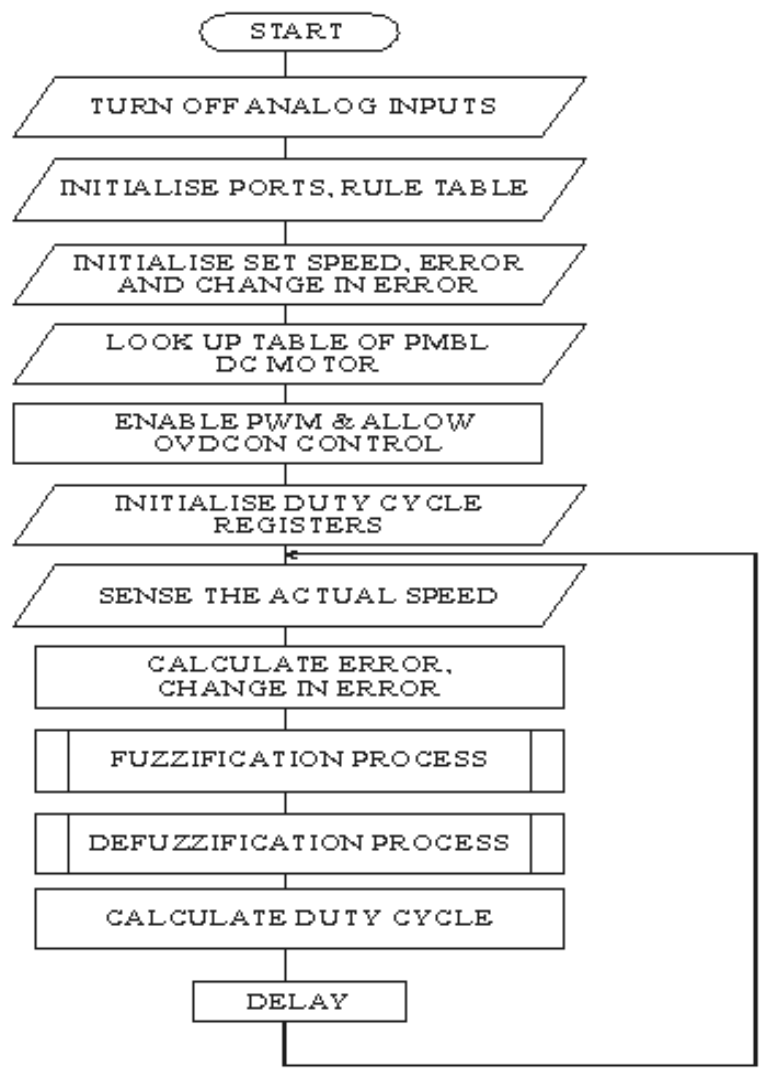

Figure 13 Flowchart of the control algorithm

\section{CONCLUSION}

From the simulation results, it is inferred that wide range of speed control is possible by means of fuzzy controller. The results are obtained without peak overshoot and with negligible steady state error. Moreover it can be noted that the controller design does not requires explicit knowledge of the motor and load characteristics. So, it can be concluded that this method of speed control of BLDC motor provides accurate results even under ill-defined nonlinear dynamics. The results of adaptive fuzzy controller are better than the fuzzy controller without adaptation. The practical 
implementations of the designed fuzzy and adaptive fuzzy controllers are discussed.

\section{REFERENCES}

1. B.K. Bose, "Power electronics and motor drives-recent technology advances", Proceedings of the IEEE International Symposium on Industrial Electronics (ISIE 2002), Italy, July 8-11,2002, Volume 1, pages 22-25.

2. C.K.Leeand, W.H.Pang, "A Brushless Motor speed control system using Fuzzy Rules" by Proceedings of the Fifth IEEE International Conference on Power Electronics and Variable, Speed Drives, UK, October 16-28, 1994, Pages 101-106.

3. Y.H. Bharathi, B.R. Rekha, P. Bhaskar, C.S. Parvathi and A.B. Kulkarni, "Multi-input Fuzzy Logic Controller for Brushless dc Motor Drives", Defence Science Journal, Vol. 58, No. 1, January 2008, pp. 147-158

4. Uddin, M.N. Radwan, T.S. Rahman, M.A. , Fuzzylogic-controller-based cost-effective four-switch threephase inverter-fed IPM synchronous motor drive system", IEEE Transactions on Industry Applications, Jan.-Feb. 2006, Volume: 42, Issue: 1, page(s): 21- 30.
5. Gwo-Ruey Yu; Chin-Wen Chuang; Rey-Chue Hwang; "Fuzzy control of brushless DC motors by gray prediction" IFSA World Congress and 20th NAFIPS International Conference, Canada, 2007. Joint $9^{\text {th }}$ Volume , Issue , 25-28 July 2007Page(s):2819 - 2824 vol.5.

6. Hailong Song Yong $\mathrm{Yu}$ Ming Yang Dianguo $\mathrm{Xu}$, "A novel SMC-fuzzy speed controller for permanent magnet brushless DC motor" Eighteenth Annual IEEE Applied Power Electronics Conference and Exposition, 2003. APEC '03, Feb. 2003 Volume: 1, On page(s): 281- 285 vol.1

7. N.Senthil Kumar, V.Sadasivam, Muruganandam, M “A Low-cost Four-quadrant Chopper-fed Embedded DC Drive Using Fuzzy Controller" Electric Power Components and Systems journal, Volume 35, Issue 8 August 2007 , pages 907 - 920

8. Dimiter Drainkov, Hans Hellendoorn and Michael reinfrank, "An introduction to fuzzy control", Narosa publishing house, New Delhi,1996 